\title{
Copper and selenium levels in women with second-trimester induced abortion in Mazandaran, 2009: A case control study
}

\author{
Zoleikha Atarod ${ }^{1}$, Nima Emadi ${ }^{2}$, Seyed Soheil Saeedi Saravi ${ }^{3}$, Mona Modanloo kordi ${ }^{4}$, Mohammad \\ Shokrzadeh $^{\text {* }}$ \\ ${ }^{1}$ Department of Gynecology, Faculty of Medicine, Mazandaran University of Medical Sciences, Sari, Iran \\ ${ }^{2}$ Pharmaceutical Sciences Research Center, Mazandaran University of Medical Sciences, Sari, Iran \\ ${ }^{3}$ Department of Pharmacology, School of Medicine, Tehran University of Medical Sciences; Tehran, Iran. \\ ${ }^{4}$ Pharmaceutical Sciences Research Center, Mazandaran University of Medical Sciences, Sari, Iran \\ ${ }^{5}$ Department of Toxicology and Pharmacology, Faculty of Pharmacy, Mazandaran University of Medical Sciences; Mazandaran \\ Pharmaceutical Research Center, Sari, Iran
}

Received: Nov 8, 2014, Revised: Jan 14, 2015, Accepted: Jan 25, 2015

\begin{abstract}
Abortion is the termination of a pregnancy by the removal or expulsion of a fetus or embryo from the uterus, resulting in or caused by its death. Missed abortion is the most common dangerous condition in pregnancy. An abortion can occur due to maternal complications, chronic disease, endocrine disorders, abortificient drugs, radiation, heavy metals and toxins. The study population consisted of 43 aborted patients and 43 normal pregnant females, referred to Imam Khomeini hospital. $10 \mathrm{~mL}$ blood was taken and centrifuged to isolate the patients' serum. Then, the samples were analyzed to determine the copper and selenium levels, using atomic absorption spectrometry. All data were statistically analyzed by T-test and Mann-Whitney methods. As a result, we found a significant decrease in serum copper level in cases compared with controls. Also the results showed an insignificant decrease in serum selenium levels in the patients compared to the healthy women. According to the results, deficiency of the essential heavy metals may be a probable reason for missed abortion occurrence. These deficiencies can be related to malnutrition, decreased consumption of essential metals and supplementary compounds in pregnancy, lack of regular laboratory monitoring. Thus, consuming supplements in Iranian pregnant women can be helpful in completing a successful pregnancy.
\end{abstract}

Keywords: Abortion, copper, selenium, serum concentration

Pharm Biomed Res 2015; 1(1): 44-47

\section{Introduction}

Abortion refers to spontaneous or induced termination pregnancy before fetus getting into sufficient evolution for survival. In fact, abortion is complete or incomplete discharge of fetus or membranes spontaneous abortion is the most common pregnancy complication. Recent studies showed that almost $10-20 \%$ of pregnancies are resulted in abortion in the firsttrimester. Bleeding is Patho-physiologically seen during menstruation period and then tissue necrosis adjacent to bleeding volume along with abortion. In mature abortion faded state of ovum and in immature abortions, fetus mashed state and in case of amniotic fluid absorption, squeezed state of fetus is seen $(1,2)$. Over $80 \%$ abortion occurs in the first 12 weeks of
DOI: 10.18869/acadpub.pbr.1.1.44

gestation and chromosomal disorders are at least in charge of half of the abortions. After the firsttrimester, abortion occurrence and chromosomal disorders are decreased. So, abortion incidence in women in the first-trimester of pregnancy is increased. The abortion occurrence is increasingly, clinically diagnosed from $12 \%$ in women younger than 20 -years to $26 \%$ in 40 years. In the first-trimester of gestation, fetus death almost occurs prior to automatic ovum discharge (3).

The abortion-induced factors include:

- Maternal factors, such as zygote abnormal evolution, aneuploid abortion and euploid abortion, etc;

- Immunological and autoimmunological factors, such as auto- 


\begin{tabular}{cl}
\hline $\begin{array}{l}\text { immune factors, inherited } \\
\text { thrombophilia, etc; }\end{array}$ & $\begin{array}{l}\text { gestation; the subjects must have no limitation } \\
\text { in their daily diet; also they were not taking any } \\
\text { medication, and had no known-vitamin }\end{array}$ \\
- Physical trauma and laparotomy (4). & $\begin{array}{l}\text { deficiency and prior significant medical } \\
\text { illnesses. All volunteers gave their written }\end{array}$ \\
$\begin{array}{l}\text { Maternal factors in abortion can be classified as } \\
\text { infections, disabling chronic diseases like } \\
\text { tuberculosis or carcinomas, endocrine disorders } \\
\text { such as hyperthyroidism, mellitus diabetes and }\end{array}$ & $\begin{array}{l}\text { informed consent before being included in our } \\
\text { study. }\end{array}$
\end{tabular}
progesterone deficiency, inappropriate diet, drugs, radiation, environmental toxins and chemicals including arsenic, lead, formaldehyde and benzene (5). It is obvious that uterus defects are the significant abortificient factors including uterus acquired defects and insufficiency. Thus, abortion incidence can be partially prevented by treatment of these defects (6). Some studies introduce a meaningful correlation between some essential micronutrients like selenium selenium, zinc and copper and reproductive risk (7). In some studies selenium presents as a part of a reproductive enzyme and there is an increase in its demand during pregnancy due to fetus uptake (8). Also copper is presented as an effective micronutrient during pregnancy (9). It presents in some tissues such as liver, kidney, spleen, heart, etc. It is also essential for some enzymes (10). Nutritional deficiencies are common during pregnancy. In developing countries it has been reported some deficits of minerals and vitamins in their diet (11).

In this study we want to evaluate two important trace elements copper and selenium $(\mathrm{Cu}$ and $\mathrm{Se})$ among normal pregnant women compare to aborted women in the greatest gynecology centre in Mazandaran.

\section{Materials and methods}

This case-control study was performed at the Department of Obstetrics and Gynecology of Imam Khomeini educational hospital of Mazandaran University of Medical Sciences in 2009. The ethical research code was $87 / 88$ that was approved in Mazandaran University of Medical Sciences. 43 pregnant women suffering from abortion at second-trimester were selected as cases. The control group $(n=43)$ consisted of women who were selected, based on the demographic information resulted from the questionnaire, among age-, gravidity-, and socio-economic status (SES)-matched women who had a normal triple-screen and targeted ultrasound during the second-trimester. Inclusion criteria: The subjects were between 20-40 years old were included; abortions must be occurred during $12^{\text {th }}$ to $14^{\text {th }}$ weeks of

\section{Blood sampling}

Overnight fasting venous blood specimens were drawn from the antecubital vein and collected into heparinized blood-collecting tubes according to standard hospital guidelines for venipuncture and sample collection. The serum separator tube specimens were allowed to clot and then were centrifuged for $2 \mathrm{~min}$ at $1500 \mathrm{rpm}$ to separate the serum. Serum samples were stored at $-20{ }^{\circ} \mathrm{C}$ until the analyses.

\section{Measurement of serum $\mathrm{Cu}$ and Se levels}

Serum $\mathrm{Cu}$ levels were analyzed in graphite furnace atomic absorption spectroscopy (AAS; Perkin Elmer Analyst 800). Samples and calibration standards for $\mathrm{Cu}$ and $\mathrm{Se}$ measurement were prepared in four concentrations with $5 \%$ and $10 \%$ glycerol. Commercial standard $\mathrm{Cu}$ and $\mathrm{Se}$ calibrators were used as standards $(1 \mathrm{mg} / \mathrm{l})$ by serial dilutions and samples were evaluated according to a standard curve (12-17). Our used AAS LOD was $0.01 \mu \mathrm{g} / \mathrm{dl}$ and its LOQ was $0.1 \mu \mathrm{g} / \mathrm{dl}$.

\section{Statistical analysis}

The prism software ver.3 (USA) was used for the statistical analysis of the mean and standard deviation of the metals concentrations in aborted and healthy subjects. The data were analyzed based on statistical-comparative quantitative tests using one way-ANOVA, Mann-Whitney test and paired t-test for multiple comparisons. A p-value of $<0.05$ was considered to be statistically significant.

\section{Results}

The patients' demographic properties such as age range, fetus abortion occurrence, the couple number being relative, unwanted gestation occurrence, the number of mothers with taking medicine during pregnancy record have been analyzed. Based on table 1 showing the highest level of embryo abortion occurring was seen in pregnant women in age rang below 25 years 
$(46 / 51 \%)$ and also the lowest level was related to women in $25-35$ age range $(23 / 25 \%)$.

Table 1 The number of women with abortion in the study in certain age range

\begin{tabular}{cccc}
\hline Age & $<$ 25 years & $\begin{array}{l}\mathbf{2 5 - 3 5} \\
\text { years }\end{array}$ & $\begin{array}{l}>35 \\
\text { years }\end{array}$ \\
\hline $\begin{array}{c}\text { Percentage } \\
(\mathrm{n})\end{array}$ & $45 / 51 \%$ & $23 / 25 \%$ & $30 / 24 \%$ \\
$(20)$ & $(10)$ & $(13)$ \\
\hline
\end{tabular}

On the other hand, based on Table 2, out of 43 pregnant women who suffered abortion, 8 couples were relative and out of control group women, only 1 couple was relative.

Table 2 Comparing two groups related to demographic information

\begin{tabular}{l|l|l}
\hline Parameter & $\begin{array}{l}\text { Suffering group } \\
\text { percentage } \\
\text { (cases/total) }\end{array}$ & $\begin{array}{l}\text { Control } \\
\text { group } \\
\text { percentage } \\
\text { (cases/total) }\end{array}$ \\
\hline $\begin{array}{l}\text { Relative } \\
\text { background }\end{array}$ & $18.6 \%(8 / 43)$ & $2.32 \%(1 / 43)$ \\
\hline $\begin{array}{l}\text { Unwanted } \\
\text { pregnancy }\end{array}$ & $32.55 \%(14 / 43)$ & $11.62 \%(5 / 43)$ \\
\hline $\begin{array}{l}\text { Family } \\
\text { abortion } \\
\text { background }\end{array}$ & $25.58 \%(11 / 43)$ \\
\hline $\begin{array}{l}\text { Medical taking } \\
\text { background } \\
\text { during } \\
\text { pregnancy }\end{array}$ & $11.62 \%(5 / 43)$ \\
\hline
\end{tabular}

The analysis of, the results indicate that unwanted pregnancies and family abortion background and taking medicine during gestation in women suffering from embryo abortion have been meaningfully higher than those of the control group. In this experiment, serum samples of women with abortion and also control group women have been analyzed in terms of essential metals such as selenium (Se) and copper $(\mathrm{Cu})$ and the relation between their serum concentration and unwanted abortion occurrence in pregnant women has been compared that the results were presented based on Table 3.

Table 3 Selenium and copper-serum concentrations in serum of women suffering from fetus abortion and control group

\begin{tabular}{l|r|r|c}
\hline Group & $\begin{array}{c}\text { Suffering from } \\
\text { abortion }\end{array}$ & Control & $\boldsymbol{P}$-value \\
Concentration & $0.779 \pm 0.16$ & $0.973 \pm 0.112$ & $\mathrm{P}>0.05$ \\
\hline Selenium & $42.326 \pm 0.176$ & $51.326 \pm 0.072$ & $\mathrm{P}<0.05$ \\
\hline Copper &
\end{tabular}

The results showed that no significant correlation was seen between abortion occurrence and the selenium serum levels in any of the groups $(\mathrm{p}>0.05)$. The serum copper concentrations in women suffering from abortion showed significant differences with the control group ( $\mathrm{p}<0.05)$. The average $\mathrm{Cu}$ and Se levels in non-pregnant subjects were $\quad 51.326 \pm 0.072$ $\mu \mathrm{g} / \mathrm{dl}$ and $0.973 \pm 0.112 \mu \mathrm{g} / \mathrm{dl}$, whereas $\mathrm{Cu}$ and $\mathrm{Se}$ levels in aborted women were $42.326 \pm 0.176 \mu \mathrm{g} / \mathrm{dl}$ with $17.64 \%$ and $0.779 \pm 0.16 \mu \mathrm{g} / \mathrm{dl}$ with $20 \%$ less, respectively (Table 3 ).

\section{Discussion}

Modification in trace element levels during pregnancy depend on many factors (15). Essential trace elements are especially important for children and pregnant women (16). The demand for both energy and nutrients is increased during pregnancy (18). Se and $\mathrm{Cu}$ are involved in many biological processes that are vital for life $(15,18)$. The results indicated that the highest incidence of secondtrimester induced abortion was occurred in pregnant women below 25 years old $(45.51 \%)$. Also, the lowest abortion incidence was seen in 25-40 years age range $(23.25 \%)$; but, following, the occurrence of abortion was increased in women above 35 years. On the other hand, genetic disorders in fetus followed may lead to some gestational disorders such as blighted ovum, defect in nestling, and missed abortion. Besides, family background of missed abortions can provide a robust genetic background for pregnant women facilitating abortion incidence due to unknown origin. For example, suffering from pre-eclampsia, pregnancy diabetes, still child born background, childbirth heavier than $4 \mathrm{~kg}$. Another influential and highly significant factor increasing unwanted abortions incidence probability is taking medicine during pregnancy. Many pregnant women take medicine willfully due to lack of knowledge about their side effects, tratogenic and provoking effects of abortion; for instance, medicine such as methatrexate , colchicines and angetansin converting enzyme controlling drugs can lead to abortion. Even taking aspirin during pregnancy can create disorders in pregnancy. Because of medicine's tratogenic effects during pregnancy, drugs have been divided into classes showing their complications levels. Thus taking drugs willfully especially when pregnant is absolutely forbidden and taking medicine should be done under doctor's supervision (12-15, 17,19). Analyzing serum selenium and copper concentrations in the serums of women with abortion and control group women indicate that both metals in the serum 
of control group suffering from abortion. Some previous studies found a significant drop in serum Se levels in aborted women compare with normal pregnant ones $(12-15,19)$.

Glutathione peroxidase (GPx) is a Se-dependent enzyme that has an antioxidant activity. Since there is an increase in free radicals and reactive oxygen species in miscarrying, Se may have an important role in abortion (20). Also $\mathrm{Cu}$ acts as a cofactor in superoxide dismutase. This antioxidant enzyme has a role in placental function (18).

\section{Conclusion}

Our study described that the trace elements levels were decreased in abortion, but more studies are needed to find out the association of lower values with any abnormalities. Therefore, essential metals such as copper and selenium deficit in pregnant women can increase the probability of unwanted abortion occurrence. The deficiency of these metals can be due to malnutrition, not pursuing medical examination during pregnancy. As a result,

\section{References}

1. Aaltonen J, Laitinen MP, Vuojolainen K, Jaatinen R, Horelli-Kuitunen N, Seppä L, et al. human growth diffrention factor 9 and its novel homolog gdf_9B are expressed in oocytes during early folliculogenesis. J Clin Endocrinal Metab 1999; 84:2744-50

2. Abel MH: prostanoids and menstruation in bird DT, Michic EA. mechanism of menstrual bleeding New york Raven , 2002, p139.

3. Albrecht Ed, Pepe GJ. steroid hormone regulation of angiogenesis in the primate endometrium FRONT Biscoci 2003; 8:d416-293.

4. Cole LA. Immunoassay of human chronic gonadotropin , its free sub units, and metabolits. Clin Chem 1997; 43:2233-43

5. Aractingi S, Berkane N, Bertheau P, Le Goué C, Dausset $\mathrm{J}$, Uzan S, et al. fetal DNA is skin of polymorphic eruptions pregnancy. Lancet 1998; 352:1898-901.

6. Carson DD. the glycobiology of implantion. Front Biosci 2002; 7:d1535-44.

7. Ajayi OO, Charles-Davies MA, Arinola OG. Progesterone, selected heavy metals and micronutrients in pregnant Nigerian women with a history of recurrent spontaneous abortion. Afr Health Sci 2012; 12: 153-9.

8. Barrington JW, Lindsay P, James D, Smith S, Roberts A. Selenium deficiency and miscarriage. a possible link? $\mathrm{Br}$ J Obstet Gynaecol 1996; 103:130-2.

9. Keen CL, Uriu-Hare JY, Hawk SN, Jankowski MA, Daston GP, Kwik-Uribe CL, et al. Effect of copper deficiency on prenatal development and pregnancy outcome. Am J Clin Nutr 1998;67: 1003S-11S.

10. Goyer RA. Toxic effects of metals. In: Amdur MO, Doull J, Klaasen CD (eds) Casarett and Doull"s Toxicology, 4th edn. Pergamon Press, New York, 1991; pp 653-655. consuming supplementary substances during pregnancy and paying attention to the genetic and family background of pregnant women, not taking drugs willfully, doing genetic tests before and during pregnancy can decrease unwanted abortions occurrence and save mother and child lives $(15,17)$. Thus, at the end, we recommend that in order to take nutrition importance in pregnant women's diet and the patients with abortion into account, sampling be done several times during several weeks and the values mean be calculated and analyzed in every woman regarding every patient's conditions.

\section{Acknowledgment}

This research project has been conducted under the financial support of Mazandaran University of Medical Sciences.

\section{Conflict of interests}

Nothing to declare.

11. Priyali $P$, Umesh K. Role of trace elements zinc, copper and magnesium during pregnancy and its outcome. Indian J Pediatr 2004; 71: 1003-5.

12. Kumar KS, Kumar A, Prakash S, Swamy K, Jagadeesan $\mathrm{V}$, Jyothy A. Role of red cell selenium in reccuremt pregnancy loss. J Oobset Gynaecol 2002; 22: 181-3.

13. Zachara BA, Dobrzyński W, Trafikowska U, Szymański W. Blood selenium and gluthatione peroxidases in miscarriage. BJOG 2001;108:244-7.

14. Nicoll AE, Norman J, Macpherson A, Acharya U. Association of reuced selenium status in the aetiology of recurrent miscarriage. Br J Obset Gynaecol 1999; 106: 1188-91.

15. Bedwal, RS, Bahuguna A. Zinc, copper and selenium in reproduction. Cell Mol Life Sci 1994; 50: 626-40.

16. Mehmet EOR, Seyyal AK, Abdullah K, Serhat A, Aydin G, Yunus K, et al. serum zinc and copper concentrations in rams experimentally infected by mycoserum aglactiae. Slov Vet Res 2005;42:31-36.

17. Cengiz B, Söylemez F, Oztürk E, Cavdar AO. Serum zinc, selenium, copper, and lead levels in women with second-trimester induced abortion resulting from neural tube defects: a preliminary study. Biol Trace Elem Res 2004;97:225-35

18. Schulpis KH, Karakonstantakis $\mathrm{T}$, Gavrili $\mathrm{S}$, Chronopoulou G, Karikas GA, Vlachos G, et al. Maternal- neonatal serum selenium and copper levels in Greeks and Albanians. Eur J Clin Nutr 2004; 58: 1314-18.

19. Al-Kunani AS, Knight R, Haswell SJ, Thompson JW, Lindow SW. The selenium of women with a history of recurrent miscarriage. BJOG 2001;108:1094-7.

20. Abdulah R, Noerjasin H, Septiani L, Mutakin, Defi IR, Suradji EW, et al. Reduced serum selenium concentration in miscarriage incidence of Indonesian subjects. Biol Trace Elem Res 2013; 154:1-6. 